\title{
Wind tunnel studies of gas dispersion over complex terrain
}

\author{
Petr Michálek ${ }^{1, a}$ and David Zacho ${ }^{1}$ \\ ${ }^{1}$ Aerospace Research and Test Establishment (VZLU), Department of Aerodynamics, Beranových 130, Praha 9, Czech Republic
}

\begin{abstract}
Wind tunnel studies of gas dispersion over complex terrain model were performed in VZLU Prague. The terrain model with a ground-level emission source was mounted in a boundary layer wind tunnel. Flow and concentration field behind the source was measured. The model presented an area of the Liberec city, $9.0 \times 2.4 \mathrm{~km}$ in full scale. The emission source was mounted at the position of a heating plant in the model centre and concentration field was measured using flame ionisation detectors. The experimental results will be used for validation and verification of a new computational dispersion model intended for use in case of accidents with dangerous gas leakages in selected areas in Czech Republic.
\end{abstract}

\section{Introduction}

There are many chemical plants in the Czech Republic and some of them present a serious risk to people living in its neighbourhood. Recent gas explosion in Litvinov has proven again the need for a tool, which will be able to predict dangerous gas dispersion in urban areas in the vicinity of selected chemical factories. Such computational dispersion model is being developed in VZLU. The model uses pre-calculated results of flow and dispersion in selected urban areas together with actual meteorological situation to estimate the most endangered area. The results will be available for rescue services in the case of an accident and for local authorities for the development of emergency plans.

Experimental studies concerning gas dispersion from ground level source were made e.g. by Hall et al. [1], Lawton and Robins [2], Yassin et al. [3]. Britter and Hanna [4] reviewed flow and dispersion in different scales. In Czech Republic, Ulman et al. [5, 6] studied dispersion in topographically complicated terrain, Nosek et al. [7], Janour et al. [8], Brych et al. [9] investigated gas dispersion from a chemical factory.

The mathematical model from VZLU is based on the numerical numerical solution of the compressible gas flow in the gravitational field, uses finite volume method for the solution of the Reynolds-Averaged Navier-Stokes equations with the k-omega or EARSM turbulence models, together with the additional equation describing mass conservation of the additional gas specie. It uses special handling of the boundary conditions, based on the analysis of the Riemann problem; see Kyncl and Pelant $[10,11]$.

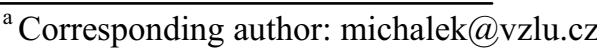

\section{Experimental setup}

The experiments were made in a boundary layer wind tunnel (BLWT) in VZLU, which an open-circuit wind tunnel with cross section $1.8 \times 1.5 \mathrm{~m}$ in model section and $13.5 \mathrm{~m}$ long test section for boundary layer development. The tunnel is powered with $55 \mathrm{~kW}$ fan behind the $2 \mathrm{~m}$ long model section. Maximal velocity above the boundary layer is ca. $25 \mathrm{~m} \mathrm{~s}^{-1}$ and the ceiling is adjustable in model and test section. The simulation means can create agricultural, suburban or urban boundary layer according to Eurocode 1 [12]. The boundary layer developed over $7 \mathrm{~m}$ long part of the test section with boards covered with glued $4 \mathrm{~mm}$ gravel and a rectangular barrier $140 \mathrm{~mm}$ high, which served as turbulence generator. Continuous transition from boards with gravel to the model was made with increasing number of layers of boards in order to reach the level of the terrain model edge. This boundary layer corresponds with terrain type III (suburban).

The terrain model was manufactured from lightweight boards on the basis of a digital terrain model of Liberec city. The model was manufactured in scale 1:1500 and presents an area of $9.0 \mathrm{~km} \times 2.4 \mathrm{~km}$ in full scale. The modeled area is in northwest-southeast direction along the valley of Lužická Nisa river and contains a heating plant as the possible source of gas leakage and its densely urbanized neighborhood. The terrain model was covered with the same $4 \mathrm{~mm}$ gravel in order to increase the aerodynamic roughness. Models of significantly high buildings and housing estates were manufactured too. Other buildings were substituted with the gravel. Windward part of the terrain model mounted in the wind tunnel is shown in Figure 1; the emission source is under the white spot. The emission source is a small chamber $25 \times 25 \times 10 \mathrm{~mm}$ covered with filtration fabric on its top 
and built in the model. The source presents a ground level point or small area source of gas emissions.

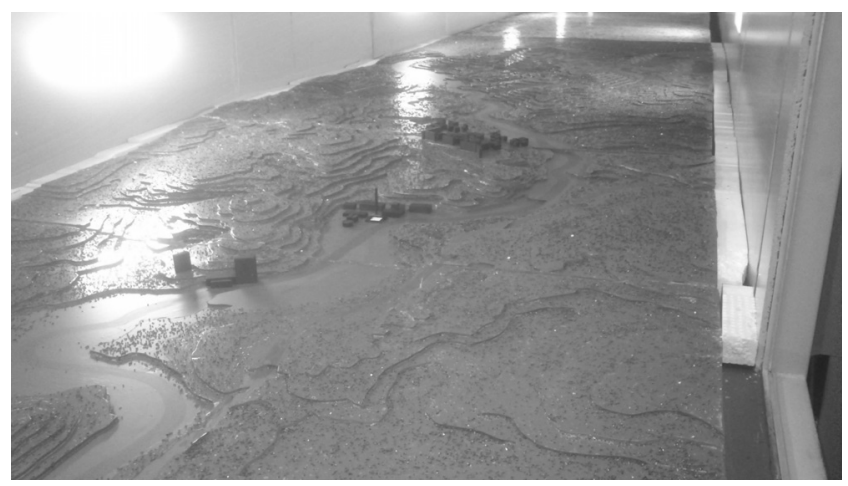

Figure 1. The terrain model of Liberec in wind tunnel

The modeled area is presented in Figure 2. The model was mounted in the wind tunnel in southeast-northwest direction, so the main flow direction was from bottom right to top left corner of the map in Figure 2.

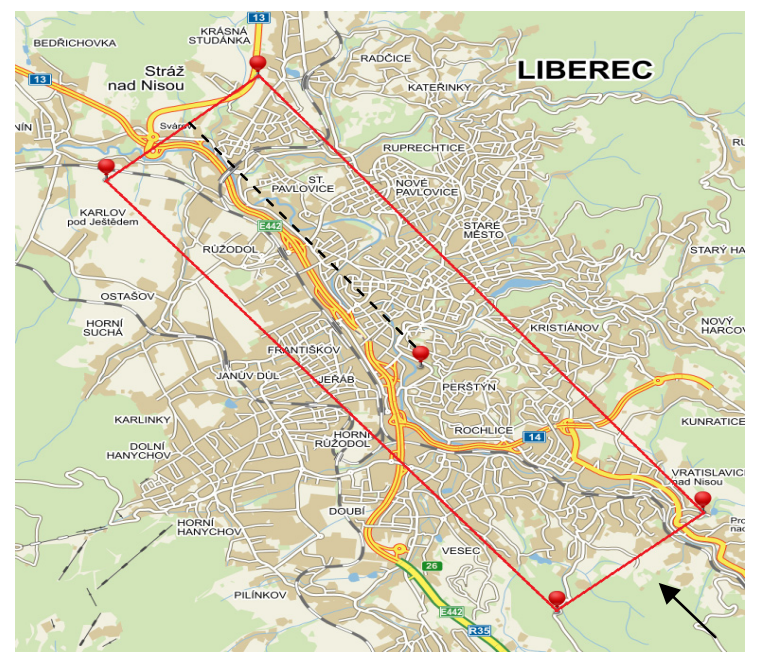

Figure 2. The modelled area of Liberec with source location

The incoming boundary layer above the emission source was measured with dual-sensor hot-wire probe and its vertical mean velocity profile is shown in Figure 3 , where $\mathrm{U}\left(\mathrm{m} \mathrm{s}^{-1}\right)$ is longitudinal component of velocity vector and $\mathrm{V}\left(\mathrm{m} \mathrm{s}^{-1}\right)$ is perpendicular velocity vector component, $\mathrm{Iu}(\%)$ is turbulence intensity of the component $U, I_{v}(\%)$ is turbulence intensity of the component $\mathrm{V}$ and $\mathrm{z}(\mathrm{mm})$ is vertical height above the emission source.

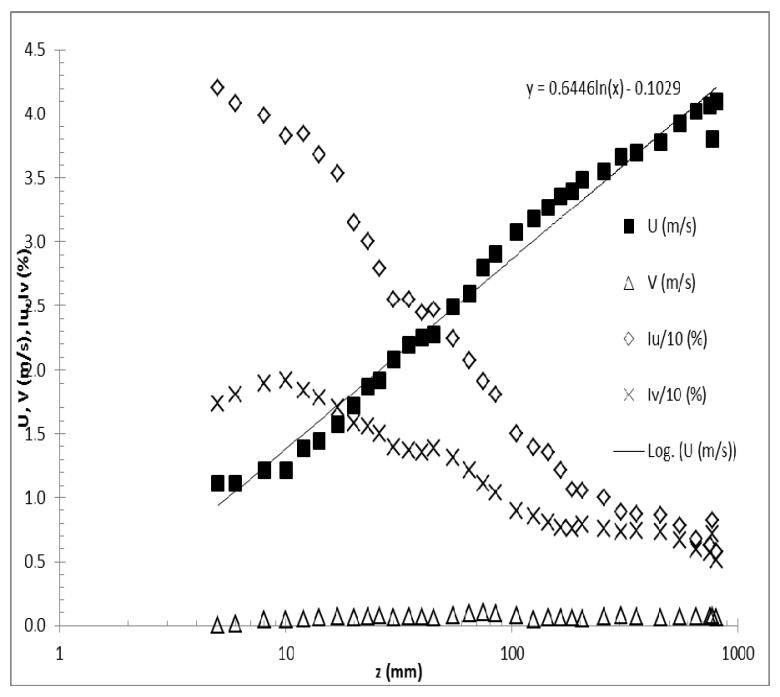

Figure 3. Vertical velocity and turbulence intensity profile

This vertical mean velocity profile was measured above the emission source and indicates that the ideal logarithmic profile differs from the actual velocity profile of component $U$ due to high turbulence caused by the hills and dense build-up areas. The reference velocity was set to ca. $4.3 \mathrm{~m} \mathrm{~s}^{-1}$ above the boundary layer and this reference velocity was used in the dispersion experiments as well. For this size of the modeled area, the so-called small-scale similarity criteria applies, which means that the minimal Reynolds roughness number $\mathrm{Re}^{*}$ has to be satisfied. This ensures invariance of the flow pattern above the structure. The Reynolds roughness number is defined as

$$
\operatorname{Re}^{*}=\mathrm{z}_{0} \times \mathrm{u}^{*} / \mathrm{v}=11.9 \geq 1,
$$

where $v$ is kinematic viscosity of air $\left(\mathrm{m}^{2} \mathrm{~s}^{-1}\right), \mathrm{u}^{*}$ is frictional velocity $\left(\mathrm{m} \mathrm{s}^{-1}\right)$ and $\mathrm{z}_{0}$ is aerodynamic roughness $(\mathrm{m})$. Values of $\mathrm{u}^{*}=0.26 \mathrm{~m} \mathrm{~s}^{-1}$ and $\mathrm{z}_{0}=1.17$ $\mathrm{mm}$ were derived from the logarithmic fit of the mean velocity profile. The turbulence spectrum in Figure 4 was evaluated at height $300 \mathrm{~mm}$ above the end of boards with gravel at the transition point from boards to the model. The measured spectrum showed good agreement with Eurocode 1 wind turbulence spectrum.

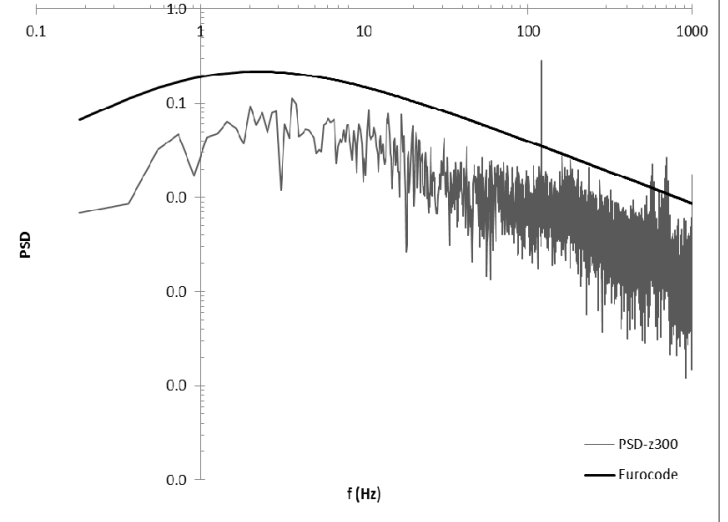

Figure 4. Power spectral density of the incoming flow 
The emission source was connected to the gas tanks with tracer gas (ethane) and compressed air source via flow controllers. For neutral (non-buoyant) emission modeling, a mixture of compressed air with volume flow $5.11 \mathrm{~min}^{-1}$ and ethane with flow $0.251 \mathrm{~min}^{-1}$ was established. For dense gas emission simulation, sulfur hexafluoride $\mathrm{SF}_{6}$ can be added into the emission mixture. Concentration field was measured using suction probe with four tubes mounted on a traversing device, necessary tubing, peristaltic pump and four flame ionization detectors (FID). FIDs measured on the principle of the hydrogen flame ionization, which changed according to burning of tracer gas (ethane) contained in the incoming sample. FID calibration was made with calibration gas mixture with precise concentration $100 \mathrm{ppm}$ (parts per million) of ethane in air. Sampling time was set to $60 \mathrm{~s}$ for one point, and then the probe moved to next point and waited $30 \mathrm{~s}$ to clean the tubing from previous sample. The response of this system is up to $10 \mathrm{~Hz}$ that is why only mean concentration values were evaluated. FID signals were recorded in the computer using analog to digital input card and LabView software.

\section{Results}

Vertical and horizontal (longitudinal and transversal) concentration profiles were measured over the entire traversing device range to examine the extent of the concentration field. Then a network of points at certain heights above the source level, i.e. 5, 15, 25, $50 \mathrm{~mm}$, etc. was measured to investigate the entire concentration field. The results were then evaluated into graphs using Excel and Origin spreadsheet software.

The measured mean concentration values $\mathrm{c}(\mathrm{ppm})$ were recalculated into dimensionless concentration

$$
c^{*}=\frac{c U_{r e f} H^{2}}{Q},
$$

where $\mathrm{c}$ is measured concentration, $\mathrm{U}_{\text {ref }}$ is reference velocity $\left(4.3 \mathrm{~m} \mathrm{~s}^{-1}\right), \mathrm{H}$ is difference between lowest and highest point in the modeled area in full scale $(135 \mathrm{~m})$ and $\mathrm{Q}$ is source volume flow $\left(5.351 \mathrm{~min}^{-1}\right)$. The concentration was measured in a network of points indicated with crosses. The horizontal longitudinal concentration profiles measured downstream the emission source at heights from 45 to $180 \mathrm{~m}$ in full scale is in Figure 5. The location of the profile is depicted in Figure 2 with dashed line. The main flow direction is from right to left. The values indicate high concentration at the lowest level and rapidly decreasing concentration with increasing distance from the source. At higher level the emission concentration raises not so much, therefore our interest should be concentrated on the lowest levels below ca. $90 \mathrm{~m}$ in full scale above the source level.

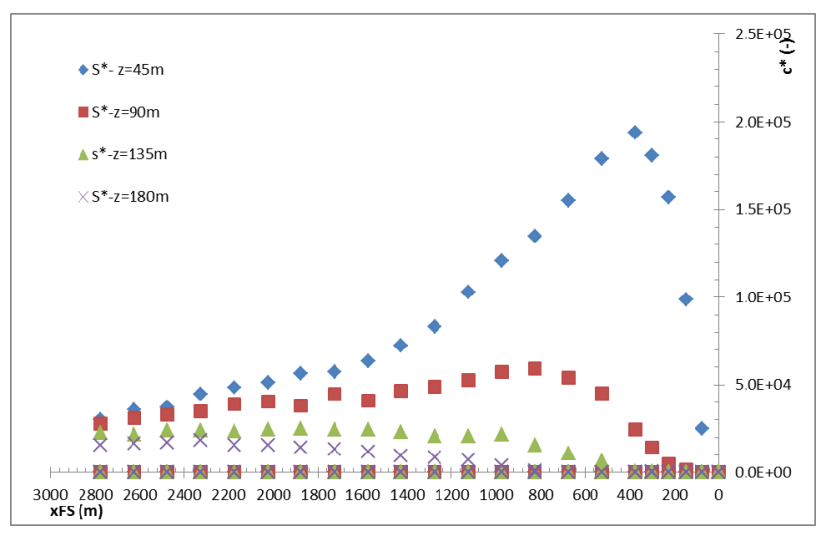

Figure 5. Horizontal longitudinal concentration profile

The resulting image from measurements within a network of points processed as contour graph at height 5 $\mathrm{mm}(7.5 \mathrm{~m}$ in full scale) above the source level is shown in Figure 6. The coordinates xFS (m) and yFS (m) are in full scale values. Crosses indicate measuring points. This height $5 \mathrm{~mm}$ was the lowest height above the model surface, where measuring was possible. Main flow direction was from right to left. The plume extension behind the source can be observed. For better evaluation of the plume in real built environment, the graph can be compared with a satellite image of the studied area within the same scale.

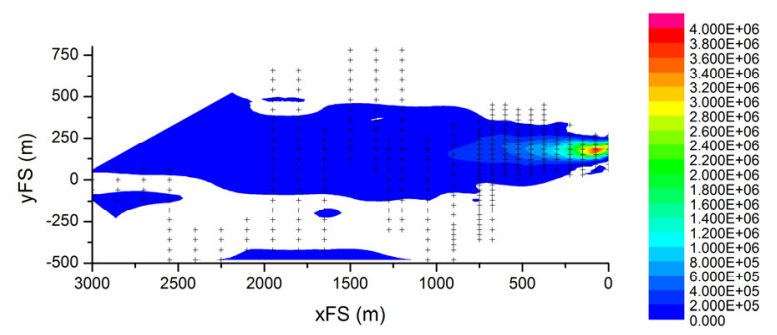

Figure 6. Concentration field $\mathrm{c}^{*}$ for $\mathrm{z}=7.5 \mathrm{~m}$ in full scale above the source level, neutral emission

\section{Conclusion}

Mean velocity profiles and concentration fields were measured over a complex terrain model of Liberec in VZLU. Mean concentration and velocity profiles and fields were measured with the use of tracer gas emission, flame ionization detectors and hot-wire probes. The extent of the plume from simulated gas leakage from a heating plant in Liberec was determined horizontally and vertically. The mean concentration fields were measured in several heights in order to use them for comparison and validation of the mathematical dispersion model. Future work includes dense gas dispersion measurements, dispersion in opposite (northwest-southeast) flow direction and field experiments with dense gas dispersion at the studied area using non-toxic tracer gas (sulfur hexafluoride). The comparison between experimental and numerical results will be made in the future as well. 


\section{Acknowledgement}

Authors appreciate the support by Ministry of the Interior of Czech Republic under project no No. VG20122015098 "Scent".

\section{References}

1. D.J. Hall, V. Kukadia, S. Walker, P. Tilz, G.W. Marsland, Proceedings of Physmod 2007 (2007)

2. T. Lawton, A. Robins, Proceedings of Physmod 2007 (2007)

3. M.F. Yassin, M. Ohba, H. Tanaka, Proceedings of 14th joint conference on application of air pollution meteorology with the air and waste management Assoc, Atlanta, Georgia, USA, 1-9, (2006)

4. R.E. Britter, S.R. Hanna, Annu. Rev. Fluid. Mech. 35:469-96 (2003)

5. R. Ulman, J. Drbohlav, D. Zachoval, Proceedings of 7th UK Conference on Wind Engineering, 201-204 (2006)

6. R. Ulman, Z. Janour, H. Sedenkova, J. Drbohlav, Proceedings of EACWE4, Prague (2005), paper \#189

7. S. Nosek, Z. Janour, L. Kukacka, K. Jurcakova, R. Kellnerova, E. Gulikova, EPL, 67 (2014)

8. Z. Janour, K. Jurcakova, K. Brych, F. Dittrt, F. Dittrich, Proc. Saf. Environ. Prot. 88 (2010)

9. K. Brych, F. Dittrt, J. Korenar, E. Houbova, Z. Janour, Proceedings of Konference Orlice 2001 (2001)

10. M. Kyncl, Numerical solution of the threedimensional compressible flow. Ph.D. thesis, MFF UK, Prague (2011)

11. M. Kyncl, J. Pelant, Technical report R-5453, VZLU, Prague (2012)

12. Eurocode 1: Actions on structures - Part 1-4: General actions - Wind loads (EN 1991-1-4), European Committee for Standardisation, Brussels (2005) 